\title{
Prevalence of respiratory disorder in the Northern population of Gujarat
}

\author{
Chandra Shekhar Purohit ${ }^{1}$, Kalpesh Patel ${ }^{2, *}$ \\ ${ }^{\mathbf{1}}$ Assistant Professor, Dept. of Tuberculosis and Reparatory Medicine, Shri Ram Murti Smarak Institute of Medical Sciences, \\ Bareilly, Uttar Pradesh, ${ }^{2}$ Assistant Professor, Dept. of Tuberculosis and Reparatory Medicine, Gujarat Adani Institute of Medical \\ Science, Kutch, Gujarat, India \\ *Corresponding Author: \\ Email: researchguide86@gmail.com
}

\begin{abstract}
Introduction: Diseases of respiratory tract are non curable diseases; however there can be increase in quality of life of individual with different types of treatment which leads to major air passages dilatation and shortness of breath improvement is achieved. It was in this context that the current study was undertaken to know the prevalence of chronic respiratory diseases in a rural area of Gujarat District in West India among people aged 20 years and above.

Material and Methods: the individual above the age of 20 years in the selected area and who agreed to participate in the study were included in the study. A sample size of 1900 were included in the study. There was administration of modified British medical research council to all the individuals included in the study for the diagnosis of bronchial asthma cases and chronic bronchitis.

Results: There were 1000 males and 900 females in the study. Majority of the population were in the age range of $20-39$ years. The crude prevalence of chronic bronchitis was estimated to be $5.64 \%$ for males as compared to $2.23 \%$ for females. The prevalence of bronchial asthma in the current study was estimated at $2.10 \%$.

Discussion \& Conclusion: The reason for the higher prevalence found in the present study is the probable, the majority of the individuals did not use the cleaner fuels in the domestic kitchens. This is found to be common practise in the rural kitchens of North Gujarat.
\end{abstract}

Keywords: Gujarat, Population, Prevalence, Respiratory Disorders.

\section{Introduction:}

The major disorders of the ageing communities that are caused by intake of tobacco use, physical activity and unhealthy diets leads to the occurrence of chronic diseases. As per the report of the WHO, $86 \%$ of the total death in Europe is by chronic disease. In low socio economic countries with lack of resources to improve life's quality the death by chronic diseases is the major problem [1].

Group of disorder of structure related to respiratory system and other disorder of airways leads to chronic respiratory diseases. Common respiratory diseases are occupational lung diseases, bronchial asthma, chronic obstructive pulmonary diseases and pulmonary hypertension [2].

Other than tobacco smoke, there are other risk factors that can lead to chronic respiratory diseases. Such risk factors include occupational chemicals and dusts, air pollution a frequent infection of respiratory tract [3]. Diseases of respiratory tract are non curable diseases, however there can be increase in quality of life of individual with different types of treatment which leads to major air passages dilatation and shortness of breath improvement is achieved [4].

Among all the chronic diseases, the burden of the chronic respiratory disease account for $8 \%$ of the burden of chronic diseases, that has the adverse effect on the sufferers of life. This results into increase in burden for both to community and the individual. At primary health care centres, the major reasons of consultation are the findings of respiratory problems. According to the results of the recent studies there has been increase in the prevalence of allergic disorders, asthma and chronic obstructive pulmonary diseases [5].

Children and adults both are said to be affected from asthma. It is estimated that majority of 300 million people irrespective of the age and ethenic background are suffering from asthma [6]. There has been increase in the population in the urban areas which has lead to the increase in the incident of asthma in the urban areas in the last two decades. By 2025 there are as many as additional 100 million people with asthma worldwide. The annual deaths worldwide due to asthma accounts for 2,50,000 individuals. When there is less access to the essential drugs there is higher rate of mortality [7].

Chronic bronchitis affects about a third of patients with chronic obstructive pulmonary disease (COPD), but also occurs in individuals with normal lung function, with prevalence estimates varying widely both in population-based studies $(2.6-16 \%)$ and among COPD patients (7.4-53\%).[8] In addition, it is associated with worse health status in affected subjects. Reported risk factors for chronic bronchitis include tobacco smoke, indoor and outdoor air pollution and occupational exposures.

It was in this context that the current study was undertaken to know the prevalence of chronic respiratory diseases in a rural area of Gujarat District in West India among people aged 20 years and above. 


\section{Material and Methods:}

The inclusion criteria in the present study includes the individual above the age of 20 years in the selected area and who agreed to participate in the study were included in the study. All the individuals who did not agreed to give consent were excluded from the study. Other individuals with presence of cardiac diseases, cancer, pulmonary tuberculosis, diabetes and pregnancy were excluded from the study.

All the individuals above the age of 20 years and meet the inclusion criteria were included in the study. A sample size of 1900 were included in the study, the minimum prevalence of $5.7 \%$ was used with confidence interval at $93 \%$ with error allow at $20 \%$.

All the individuals included in the study were asked to sign the informed consent. The consent was obtained from all the individuals. Once the informed consent was obtained all the individuals were subjected to two step study. The first step was to collect the demographic information from each of the respondents. Second step includes the administration of modified british medical research council to all the individuals included in the study for the diagnosis of bronchial asthma cases and chronic bronchitis.

A detailed history of the clinical symptoms were obtained and recorded. All the individuals were asked to avoid certain things like wearing clothes that could hamper the activity of the chest and restrict the expansion of abdomen, not to eat full diet within the 2 hours of test and not to perform any exercise within 30 mins of testing. The data was collected, tabulated and analysed using SPSS version 15. Data was expressed in term of percentage. Chi square test was used for the analysis and value less than 0.05 were taken as statistically significant.

\section{Results:}

Total of 1900 individuals were included in the study. Both males and females were included in the study. The entire individuals were of more than 20 years of age. There were 1000 males and 900 females in the study. Majority of the population were in the age range of $20-39$ years. In concerned for the occupation majority of the population answered that they were in the occupation of cultivation. According to the UdaiParikh scale to assess the socioeconomic status, the majority of the individuals were belonging to the middle class $(34.80 \%)$ and other $22.5 \%$ were belonging to the lower class. The chronic bronchitis was estimated to be $5.65 \%$ for males as compared to females that was $2.23 \%$. [Table 1].

With the increase in age there was found to be increased in prevalence. Older age individuals showed the higher prevalence. This was found to be similar for both the genders. There was statistical significance for the individuals with chronic bronchitis as per age. In the present study the prevalence of bronchial asthma was estimated to be $2.10 \%$ (Table 2). When the association between age and bronchial asthma was searched it was found to be non significant.

Table 1: Demographic prevalence of chronic bronchitis in study population

\begin{tabular}{|l|c|c|c|c|c|c|}
\hline \multirow{2}{*}{$\begin{array}{c}\text { Age in } \\
\text { years }\end{array}$} & \multicolumn{2}{|c|}{ Males } & \multicolumn{2}{c|}{ Females } & \multicolumn{2}{c|}{ Total } \\
\cline { 2 - 7 } & Cases & $\begin{array}{c}\text { Study } \\
\text { Population }\end{array}$ & Cases & $\begin{array}{c}\text { Study } \\
\text { Population }\end{array}$ & Cases & $\begin{array}{c}\text { Study } \\
\text { Population }\end{array}$ \\
\hline $20-49$ & 15 & 815 & 5 & 750 & 20 & 1565 \\
\hline $50 \&$ above & 50 & 185 & 20 & 150 & 70 & 335 \\
\hline Total & 65 & 1000 & 25 & 900 & 90 & 1900 \\
\hline
\end{tabular}

Table 2: Demographic prevalence of bronchial asthma in study population

\begin{tabular}{|l|c|c|c|c|c|c|}
\hline \multirow{2}{*}{$\begin{array}{c}\text { Age in } \\
\text { years }\end{array}$} & \multicolumn{2}{|c|}{ Males } & \multicolumn{2}{c|}{ Females } & \multicolumn{2}{c|}{ Total } \\
\cline { 2 - 7 } & Cases & $\begin{array}{c}\text { Study } \\
\text { Population }\end{array}$ & Cases & $\begin{array}{c}\text { Study } \\
\text { Population }\end{array}$ & Cases & $\begin{array}{c}\text { Study } \\
\text { Population }\end{array}$ \\
\hline $20-49$ & 10 & 880 & 8 & 750 & 20 & 1530 \\
\hline $50 \&$ above & 10 & 120 & 12 & 150 & 70 & 270 \\
\hline Total & 20 & 1000 & 20 & 900 & 40 & 1900 \\
\hline
\end{tabular}

\section{Discussion:}

Prevalence of self reported asthma was $2.82 \%$ and that of chronic bronchitis was $6.19 \%$ in the current study. Several estimates of current asthma point to rates ranging from $1.2 \%$ in Belgium to as high as $25.5 \%$ in Australia [9].

In the INSEARCH study done in Trivandrum in the individual with age more than 35 years, the asthma prevalence was found to be $4.45 \%$ and the prevalence of chronic bronchitis was found to be $13.5 \%$. In the present study the combined prevalence of chronic bronchitis and bronchial asthma was found to be $7.70 \%$. However when the individual prevalence was calculated it was found to be $5.60 \%$ for chronic bronchitis and $2.10 \%$ for bronchial asthma, the result are in conformity with the studies previously done.

The reason for the higher prevalence found in the present study is the probable, the majority of the individuals did not use the cleaner fuels in the domestic kitchens. This is found to be common practise in the 
rural kitchens of North Gujarat. There is division of areas of urban and rural areas in Gujarat. The prevalence in urban Gujarat was found to be $5.7 \%$ for chroninc bronchitis. Similar results were obtained by Chhabra et al. in the study done in New Delhi.

A good proportion of individuals with CRD in the community had never smoked. Higher rates of external risk factors, including secondary smoking and indoor air pollution from the burning of biomass fuels could be the reason for CRDs among people without smoking history. Indoor air pollution from domestic fuel combustion could be a significant factor for high prevalence of chronic respiratory diseases. Similarly high prevalence in females highlights the importance to address risk factors other than smoking. Although India has devised a programme to combat cancer, diabetes, cardio vascular disease and stroke, none have been devised for chronic respiratory illness till date. Considering high prevalence and its contributions to morbidity and mortality, a comprehensive programme to tackle CRDs is needed.

\section{References:}

1. Schmidt MI, Duncan BB, e Silva GA, Menezes AM, Monteiro CA, Barreto SM, Chor D, Menezes PR: Chronic non-communicable diseases in Brazil: burden and current challenges. The Lancet 2011;377:1949-61.
2. Yeadon M: Combination of a dopamine D2-receptor agonist and tiotropium or a derivative therof for treating obstructive airways and other inflammatory diseases. Google Patents, 2007.

3. Pauwels RA, Buist AS, Calverley PM, Jenkins CR, Hurd SS: Global strategy for the diagnosis, management, and prevention of chronic obstructive pulmonary disease: NHLBI/WHO Global Initiative for Chronic Obstructive Lung Disease (GOLD) Workshop summary. Am J Respir Critical Care Med 2001;163:1256-76.

4. Harrison C, Falvo D, Weiss V, Holland BE: Medical and psychosocial aspects of chronic illness and disability: Jones \& Bartlett Learning, 2017.

5. Bousquet J, Khaltaev N, Cruz AA, Denburg J, Fokkens W, Togias A, Zuberbier T, Baena-Cagnani C, Canonica G, Van Weel C: Allergic rhinitis and its impact on asthma (ARIA) 2008. Allergy 2008;63:8-160.

6. Baïz N, Annesi-Maesano I: Is the asthma epidemic still ascending? Clin Chest Med 2012;33:419-29.

7. Pimentel D, Cooperstein S, Randell H, Filiberto D, Sorrentino S, Kaye B, Nicklin C, Yagi J, Brian J, O'hern $\mathrm{J}$ : Ecology of increasing diseases: population growth and environmental degradation. Human Ecol 2007;35:653-68.

8. Leino T: Epidemiology of skin and respiratory diseases among hairdressers. 2001.

9. Viswanathan K, Rakesh P, Balakrishnan S, Shanavas A, Dharman V: Prevalence of chronic respiratory diseases from a rural area in Kerala, southern India. Ind $J$ Tuberculosis 2018;65:48-51.

How to cite this article: Purohit C. S., Patel K. Prevalence of respiratory disorder in the Northern population of Gujarat. IP Indian J Immunol Respiratory Med 2018;3(3):147-149. 